\title{
PHYSIOLOGICAL APPARATUS IN THE WELLCOME MUSEUM. 3. EARLY SPHYGMOMANOMETERS
}

\author{
by \\ CHRISTOPHER LAWRENCE*
}

THERE ARE no totally satisfactory accounts of the history of blood pressure measurement in the nineteenth century. ${ }^{1}$ Still less are there sources to indicate the type of instruments available or their manufacturers. ${ }^{2}$ Of the relation between the experimental development of these instruments and their actual use in medical practice we are almost totally ignorant. ${ }^{3}$ In the following account I shall do no more than depict the scientific and technical environment in which the first sphygmomanometers were produced, and record the literature in which they were described.

Blood pressure measurement is customarily traced back to Stephen Hales and then through the work of Poiseuille, Ludwig, and Faivre. ${ }^{4}$ All the methods developed by these men required arterial puncture. In fact, by the third quarter of the nineteenth century direct measurement of the blood pressure had become highly sophisticated, even extending to recording from within the heart's chambers. ${ }^{5}$ Blood pressure

*Christopher Lawrence, M.B., Ch.B., M.Sc., Medical Historian to the Wellcome Museum at the Science Museum, South Kensington, London SW7 2DD.

1 Undoubtedly the best account is N. Vaschide and J. M. Lahy, 'La technique de la mesure de la pression sanguine particulièrement chez l'homme', Arch. gén. Méd., 1902, 2: 349-383, 450-501, 602-639. Also useful is C. Ozanam, La circulation et le pouls, Paris, J. B. Baillière, 1886. An extremely helpful, though selective guide to nineteenth-century cardiovascular physiology is E. A. Schäfer, Textbook of physiology, Edinburgh, Young J. Pentland, 1900. See also Alfred P. Fishman and Dickinson W. Richards, Circulation of the blood: men and ideas, New York, Oxford University Press, 1964. Ralph H. Major, 'The history of taking the blood pressure', Ann. med. Hist., 1930, 2: 47-55. Jeremy Booth, 'A short history of blood pressure measurement', Proc. Roy. Soc. Med., 1977, 70: 793-799. The latter wrongly dates Marey's sphygmograph to 1881 : it was in fact invented in 1860 .

2 For an indication of the range of instruments available and some useful, though unreferenced, material on their invention and operation, see The Reichert Collection: illustrative of the evolution and development of diagnostic instruments and techniques in medicine, Handbook, 1942. This collection was on display at the Wellcome Exhibition Galleries in New York in 1942. I have been unable to trace its current whereabouts.

' The one serious attempt to assess the historical relations of medicine and its technology is Stanley Joel Reiser, Medicine and the reign of technology, Cambridge University Press, 1978.

4 S. Hales, Statical essays, London, W. Innys \& R. Manby, 1733. C. Ludwig, 'Beiträge zur kenntniss des Einflusses der Respirationsbewegungen auf den Blutlauf im Aortensysteme', Müllers Archiv. Anat. Physiol. Wissensch. Med., 1847, pp. 242-302. J. Faivre, 'Etudes expérimentales sur les lesions organiques du coeur', Gaz. méd. Paris, 1856, p. 727.

${ }^{5}$ E. J. Marey, Physiologie médicale de la circulation du sang, Paris, Adrien Delahaye, 1863. On this technique, see Hebbel E. Hoff and L. A. Geddes, 'A historical perspective on physiological monitoring: Chaveau's projecting kymograph and the projecting physiograph', Cardiovasc. Res. Bull., 1975, 14: 3-35. 


\section{Short Articles}

measurement, however, remained in the field of experimental physiology for, besides the technical reasons, it seemed to have little obvious clinical value.

The first instrument that was used to record the blood pressure indirectly in man was the sphygmograph. Of these instruments, that invented by Marey in 1860 was the most popular. ${ }^{6}$ The sphygmograph can be used to determine the blood pressure by discovering the weight required to obliterate the radial pulse. Using this technique some brilliant experimental work was done by a few investigators, notably $\mathrm{F}$. A. Mahomed, and T. L. Brunton. ${ }^{7}$ In general though, the sphygmograph proved a disappointment in this direction.

In the first place it gave only a measure of the total pressure not pressure per unit area, since it took no account of the size of the artery surface compressed. As Clifford Allbutt explained, "[it] was as if one were to mistake the total pressure of a large boiler for its pressure per square inch-a pressure of course which may be equal in boilers of very unequal dimensions". ${ }^{8}$ Besides this there were other difficulties, "The quantities, properties, and inequalities of the structures of the limb containing the artery; the unequal and unstable application of the pad along the vessel; the lie and pressure of the instrument on the whole underlying wrist; the calibre of the artery". ${ }^{9}$

The few physicians who were interested in blood pressure in this period were, as Allbutt says, “. . . driven back upon the first, the readiest and still least dispensable of pulse gauges, namely the finger". 10

Over the relative merits of pulse and instrument as an indicator of the condition of the vascular system a controversy raged within the medical profession until at least the first World War. But the finger, like the sphygmograph, only gives a measure of total pressure. The very first simple instruments purposely constructed for indirectly measuring the blood pressure were designed to measure the pressure exerted by the finger palpating the radial artery. The first was constructed by Louis Waldenberg in 1877 and varations were later described by A. M. Bloch, Jules Chéron, and J. L. Hoorweg. ${ }^{11}$ Of these early instruments the Wellcome Museum** contains one made by Verdin for Bloch (Fig. 1). The foot of the instrument is placed against the nail of

- E. J. Marey, 'Recherches sur l'état de la circulation d'après les caractères du pouls fournis par le nouveau sphygmographe', J. Physiol. Homme Animaux, 1860, 3: 241-274. On Marey, see Christopher Lawrence, 'Physiological apparatus in the Wellcome Museum. I. The Marey sphygmograph', Med. Hist., 1978, 22: 196-200.

${ }^{7}$ For an account of this work and references see Lawrence, ibid., and 'Physiological apparatus in the Wellcome Museum. 2. The Dudgeon sphygmograph and its descendants', Med. Hist., 1979, 23: $96-101$.

B Clifford Allbutt, Diseases of the arteries including angina pectoris, London, Macmillan, 1915, vol. 1, p. 65 .

Ibid., p. 58.

${ }^{10}$ Ibid., p. 61.

${ }^{11}$ Louis Waldenburg, 'Die Pulsuhr ein Instrument zum Messen der Spannung Füllung und Grosse des menschlichen Pulses', Berlin Med. Gesell. Verhandl., 1877, 8: 75-99; A. M. Bloch, 'Nouveau sphygmomètre', Paris, Soc. Biol. Mém., 1888, 40: 84-86; J. L. Hoorweg, 'Ueber die Blutbewegung in den menschlichen Arterien', Pflüger, Arch. Physiol., 1890, 46: 115-118; 47: 439-457. Chéron apparently did not publish an account of his instrument. The Reichert Catalogue, op. cit., note 2 above, describes it as a modification of Bloch's and dates it c.1885.

**The Museum of the Wellcome Institute for the History of Medicine is currently being transferred to the Science Museum, South Kensington, London, on indefinite loan, where it will form the Wellcome Museum of the History of Medicine. 


\section{Short Articles}

the palpating finger and the pressure is supplied by the spring of the instrument itself. The systolic pressure is read on the calibrated scale when the pulse is totally obliterated. When using this instrument it is essential that the palpating finger remain totally passive. Practice with the instrument soon demonstrates that this is not easy, and that readings are subject to much variation. As with the finger and the sphygmograph, this instrument records only total pressure, neither does it give any indication of the diastolic pressure.

During the 1870s the problem of measuring the absolute pressure had been simultaneously tackled by several physiologists. In $1875 \mathrm{~N}$. von Kries, in Ludwig's laboratory, measured the tension of the skin capillaries by the weight required to blanch the skin in a designated spot. ${ }^{12}$ The absolute or hydrostatic pressure could be determined since the size of the compressed surface could be easily measured. Following this, Marey used air to compress the arm which was contained in a glass box, and he regarded the blanching of the arm as equal to the systolic pressure. ${ }^{13}$ This, of course, was a way of measuring the absolute pressure, for the air pressure indicated by the manometer is that exterted by the air on each point of the skin. Marey, however, modified this method since other factors, such as neural control, are involved in blanching of the skin. Instead of using air Marey filled the box with water and connected it to a tambour which recorded the arterial pulsations on a revolving drum. The glass box was also connected with a mercury manometer and with a movable reservoir to raise and lower the pressure. The pressure was gradually varied around the arm until the sphygmograph no longer recorded any pulsations. This was taken as the systolic pressure. ${ }^{14}$ In 1878 Marey simplified this method by enclosing the finger alone in a water-containing tube. ${ }^{15}$ These two methods are, however, quite inaccurate since it is not possible to limit exactly the point at which the volume alterations of the arm accompanying those of the pulse disappear. Von Basch and Breuer found the instrument registering vibrations at pressure of $400 \mathrm{~mm} \mathrm{Hg}$. This they suggested was due to the thrust from the pulse in the upper arm being transmitted through the elastic obstruction of the water around the forearm. ${ }^{16}$

In 1878 C. S. Roy and Graham Brown described a method of measuring the blood pressure in the frog's web. ${ }^{17}$ Essentially the technique involved indirectly compressing the skin by air, since the air was enclosed within a capsule with a membrane to transmit changes in pressure.

It was from these two experimental approaches, the use of the solid pulse compressor and the fluid technique, that Samuel Siegfried Ritter von Basch was able to synthesize the prototype of the modern sphygmomanometer. Basch was born in Prague in

\footnotetext{
12 N. von Kries, 'Ueber den Druck in den Blutcapillaren den menschlichen Haut', Leipzig, Math. Phys. Ber., 1875, 27: 149-160; Leipzig, Physiol. Anst. Arbeit., 1876, 10: 69-80.

18 Physiologie expérimentale: Travaux du laboratoire de M. Marey, Paris, G. Masson, 1876, vol. 2, pp. 309-331.

14 Ibid.

16 Ibid., 1880, vol. 4, pp. 253-257.

${ }^{16} \mathrm{~S}$. von Basch, 'Ueber die Messung des Blutdrucks am Menschen', Zt. Klin. Med., 1880, 2: 79-96.

17 C. S. Roy and J. G. Brown, 'The blood pressure and its variations in the arterioles, capillaries and smaller veins', J. Physiol., 1880, 2: 323-359.
} 


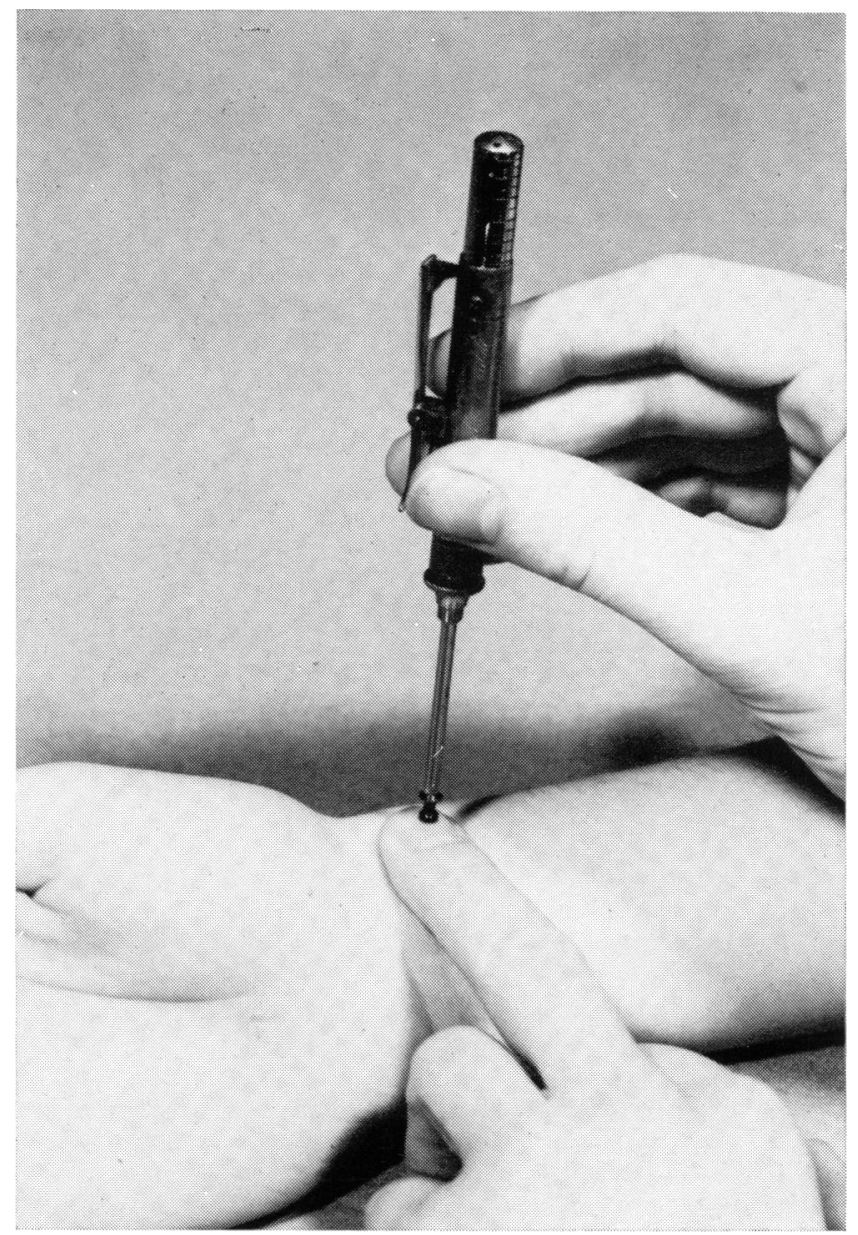

Figure 1.

An instrument designed by Bloch and modified and made by Charles Verdin of Paris. Graduated from $30-270 \mathrm{~mm} \mathrm{Hg}$ and 100-1300 Gr. Made of brass and steel and in excellent working order. Length $14.1 \mathrm{~cm}$. - -A600404. 


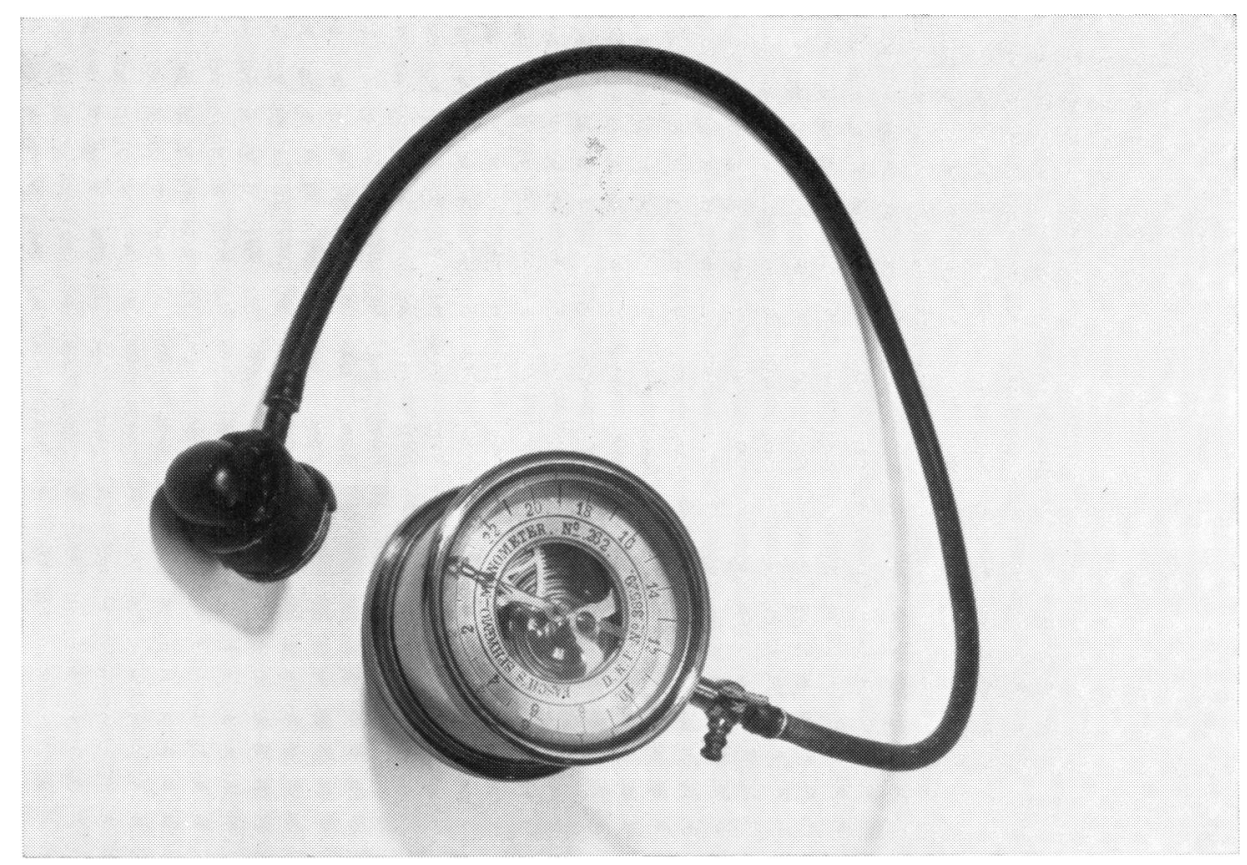

Figure 2

A slightly later version of von Basch's earliest instrument. The metal case is $5.0 \mathrm{~cm}$ diameter and contains a Vidie capsule and a scale graduated from 0-220 mm $\mathrm{Hg}$. This model, which was still a water-filled instrument, was patented by von Basch in 1886 . Deutsches Reich Patentschrift (DRP) 38529. This instrument is numbered 269. It formerly belonged to Thomas Lauder Brunton. A600275. 


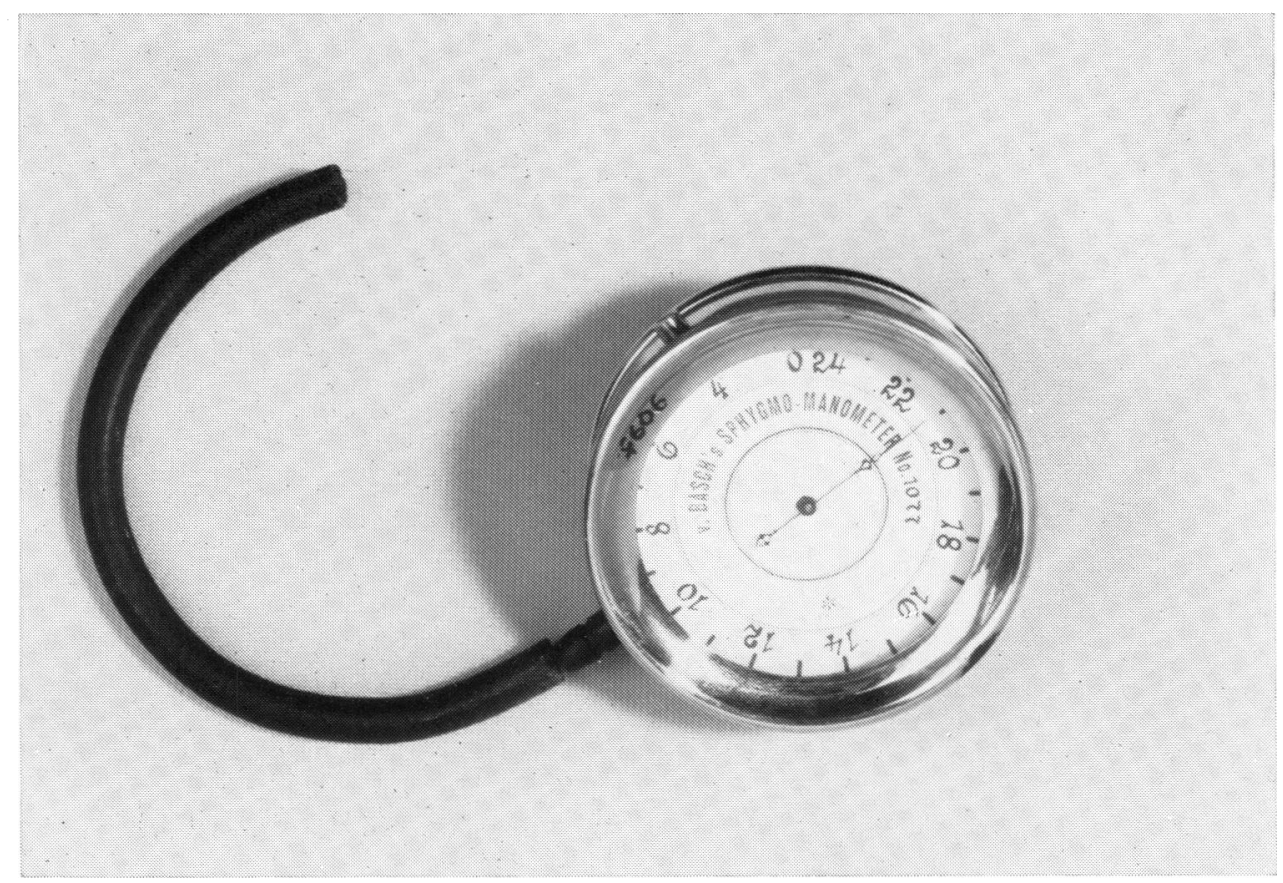

Figure 3.

The manometer from a von Basch instrument. This model, which contains a Bourdon tube, was presumably produced after 1895 (see text), $5.5 \mathrm{cms}$ in diameter and numbered "von Basch's sphygmomanometer No. 1077". The mechanism is not visible as opposed to the instrument in Figure 2. Graduated from 0-240 mm Hg. It formerly belonged to Thomas Lauder Brunton. A600420. 


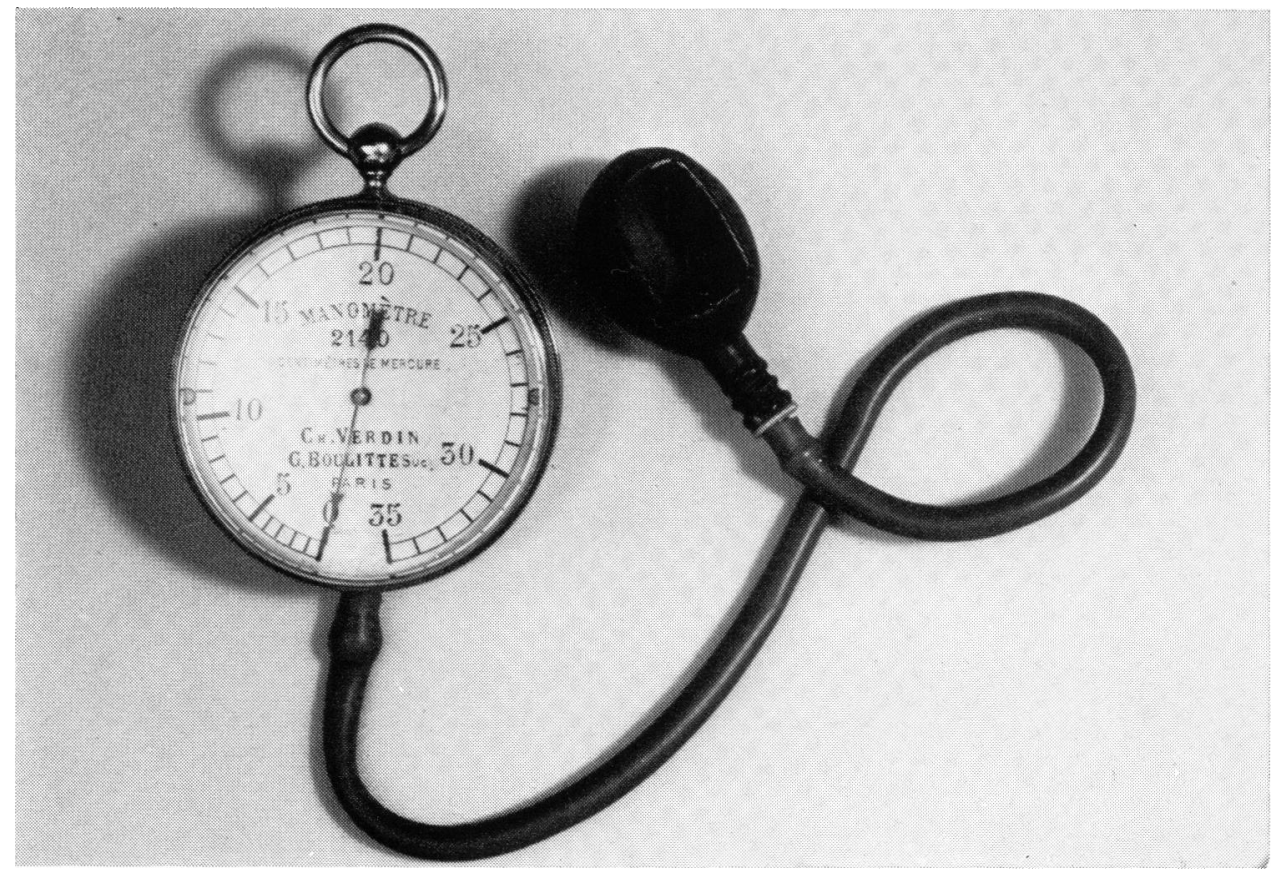

Figure 4

A Potain sphygmomanometer. Made by Charles Verdin of Paris. $5.1 \mathrm{~cm}$ diameter and graduated from $0-320 \mathrm{~mm} \mathrm{Hg}$, it lacks the side attachment for replenishing the air. It formerly belonged to Thomas Lauder Brunton. A600273. 


\section{Short Articles}

1837, and after working for a period with Ernst Brücke and then in Mexico, he became professor of physiology in Vienna in $1877 . .^{18}$ Basch described the instrument he called the "sphygmomanometer" in $1880 .{ }^{19}$ It consisted of a thick-walled glass tube containing mercury which opened out into a small knob connected to a membraneous bulb filled with water. This "pelotte" was placed on the artery until the pulse was obliterated. The instrument must have been difficult to handle as Basch made his measurements by combining it with a sphygmograph which registered the obliteration of the pulse.

Though an excellent laboratory device, the instrument was hardly suitable for everyday use. It was fairly rapidly modified by Basch and others though the principle remained identical. The first major modification was almost certainly made by Basch himself when he replaced the mercury manometer by an anaeroid type. The anaeroid manometers used were modifications of the fairly common anaeroid barometer, the principle of which is first found in Leibniz's correspondence. ${ }^{20}$ One or two models were actually constructed during the eighteenth century, but the modern barometer owes its name and usual form to the inventor Lucien Vidie (1805-1866). ${ }^{21}$ Basically Vidie's barometer, patented in 1844, consisted of an evacuated metal capsule supported internally by helical springs. The capsule dilated and contracted in response to changes in air pressure. The barometer underwent gradual refinement during the century and by 1861 a pocket-sized instrument had been produced. It was also in the 1840s that the other major type of anaeroid barometer was described and made. In 1846 a German railway engineer called Carl Schinz discovered that a curved tube of elliptical cross-section changes its curvature when subjected to internal pressure. Eugène Bourdon, a Paris instrument-maker, patented the construction in 1849. It was used throughout the nineteenth century as a steam gauge on locomotives. As the basis of the barometer though, the "Bourdon tube" was relatively neglected during the nineteenth century in favour of Vidie's capsule. The Bourdon tube did however find a use in physiology as the basis of Fick's kymograph. ${ }^{22}$

In June 1883 Basch published an illustrated account of a sphygmomanometer he had had made (Fig. 2). ${ }^{23}$ It consisted of a small pelotte filled with water and connected by a flexible tube to a Vidie capsule which in this case was not evacuated but contained water continuous with that in the capsule. There was also a side arm for introducing more water if necessary. The instrument had a circular dial and registered pressures between 0-300 mm. of mercury. Basch gave no dimensions, but from the illustration it was clearly of "pocket size". In use the pelotte was applied to the radial artery with one hand whilst the other felt the pulse below it. Pressure was increased

\footnotetext{
18 Marlene Jantsch, 'Samuel von Basch', Wien. med. Wschr., 1955, 105 : 323-326.

10 Von Basch, op. cit., note 16 above. There is an English translation of this paper in Arthur Ruskin, Classics in arterial hypertension, Springfield, Ill., Charles C Thomas, 1956, pp. 83-102.

${ }^{20}$ W. E. Knowles Middleton, The history of the barometer, Baltimore, Md., The Johns Hopkins Press, 1964, p. 398.

21 Ibid. Middleton's biography of Vidie contains an intriguing but opaque remark on the state of the French legal profession in the nineteenth century. "Lucien Vidie born at Nantes (Loire-Inférieure), was destined for the bar; but he was of an extremely sensitive and retiring disposition and left the legal profession in 1830 and went in for steam engineering" (p. 400).

${ }^{22}$ A. Fick, 'Ueber ein neues Kymographion', Dt. Naturf. Ber., 1864, 39: 188.

23 S. von Basch, 'Ein Metall-Sphygnomanometer', Wien. med. Wschr., 1883, 33: 673-675.
} 


\section{Short Articles}

on the pelotte until the pulse disappeared and the systolic pressure was read on the manometer. In his paper Basch gave no reason for choosing a metal capsule rather than a Bourdon tube but indicated that in theory alternatives were available.

In 1896 Basch reviewed the history of his work in sphygmomanometry. ${ }^{24} \mathrm{He}$ recounted that when he began his work he had wished to use a Bourdon tube as the basis of the manometer. However, he had been unable to discover either in Austria or abroad an instrument-maker who would undertake to make one of the appropriate size. Barometers all utilized Vidie capsules. Finally, in 1895 he found an instrumentmaker who could construct a manometer using a Bourdon spring. It was, he recounted, entirely satisfactory. A Basch sphygmomanometer with a Bourdon tube can thus be fairly accurately dated (Fig. 3).

A significant modification of the Basch anaeroid instrument was made by Pierre Carl Edouard Potain (1825-1907), who was professor of clinical medicine at the Charité, Paris. ${ }^{25} \mathrm{He}$ had begun his studies in blood pressure as early as 1863, and in 1889 he published an account of his sphygmomanometer ${ }^{26}$ (Fig. 4). Potain's instrument was a simple anaeroid manometer utilizing a metal capsule attached to a pelotte, but it differed from Basch's instrument in that it contained air. Potain stated that he had been using the instrument since July 1883, one month after Basch's account had been published. Basch in turn stated that his later instruments, presumably after 1889, utilized air instead of water in consequence of Potain's example.

These instruments essentially remained as tools of research among a few specialists in the British medical profession, such as Thomas Lauder Brunton and Clifford Allbutt. The British Medical Journal or the Lancet contained no articles on the sphygmomanometer until Hill and Barnard published an account of their instrument in 1897. ${ }^{27}$ Thereafter references remained infrequent until well into the twentieth century when, for both technical reasons and because of a change in attitude of the profession towards clinical medicine, the instrument was to become an essential part of the physician's arsenal.

In a future publication I shall survey later instruments and suggest reasons for their eventual incorporation into everyday medical practice.

${ }^{24}$ S. von Basch, 'Fünfzehn Jahre Blutdruckmessung', ibid., 1896, 46: 617-620.

${ }^{25}$ B. Barker Beeson, 'Potain: His life and works', Bull. Soc. Med. Hist. Chicago 1928-35, 4: $142-150$.

${ }^{26}$ P. C. E. Potain, 'Du sphygmomanomètre et de la mesure de la pression artérielle chez l'homme', Arch. Physiol., 1889, 1: 556-569.

${ }^{27}$ Leonard Hill and Harold Barnard, 'A simpler and accurate form of sphygmomanometer or arterial pressure gauge contrived for clinical use', Br. med. J., 1897, ii: 904. 